\title{
AVALIAÇÃO DAS MUDANÇAS NO ESTILO DE VIDA DOS RESIDENTES EM CONTEXTO DE PANDEMIA
}

Felipe Leonardo Rigo Fundação Hospitalar do Estado de Minas Gerais felipeleonardorigo@hotmail.com

Thiago Teixeira de Souza Hospital Infantil João Paulo II Fundação Hospitalar do Estado de Minas Gerais thiagoyai@hotmail.com

Thaís Pereira Lopes de Souza Hospital Infantil João Paulo II Fundação Hospitalar do Estado de Minas Gerais thaispls@1ive.com

Elizabeth Iracy Alves Leite Hospital Infantil João Paulo II Fundação Hospitalar do Estado de Minas Gerais bebel.leite@gmail.com

INTRODUÇÃO: Estudos reportam o aumento do consumo de substâncias lícitas e ilícitas associados à crise sanitária causada pelo COVID-I9, com destaque para as bebidas alcoólicas. A preocupação com o consumo abusivo que deve ser investigado entre estudantes e profissionais de saúde durante a pandemia pois, estudos trazem que nesse grupo devido à natureza estressante e exaustiva de suas funções laborais habituais e estando na linha de frente de combate ao novo coronavírus podem favorecer para o consumo abusivo do álcool. OBJETIVO: Investigar o padrão de consumo de bebidas alcoólicas entre os residentes médicos e multiprofissional durante a pandemia da COVID-19 METODOLOGIA: Estudo transversal, descritivo e quantitativo, realizado em um hospital infantil, referência e localizado no município de Belo Horizonte, Minas Gerais. Para a coleta dos dados utilizou-se dois instrumentos, sendo o primeiro um questionário semi-estruturado composto por questões do perfil sociodemográfico. Já o segundo instrumento consiste no teste de investigação do padrão de consumo de bebidas alcoólicas (AUDIT). Estudo aprovado pelo Parecer: $n^{\circ}$ 34.I30.30I. RESULTADOS: A amostra foi composta por 38 participantes, sendo (42\%) residentes médicos e (58\%) multiprofissional, sexo feminino (89,47\%), faixa etária entre 18 e 29 anos (81,58\%), cor branca $(65,79 \%)$, solteiros (92,11\%). O hábito de consumir álcool foi de (65,79\%). Houve aumento do consumo em decorrência da pandemia em (7,89\%). As bebidas mais consumidas foram a cerveja $(23,68 \%)$ e o vinho (16\%). Entre as principais razões para o consumo foi citado socializar (I5,79\%), relaxamento (I3,I6\%) e em momentos de lazer e recreação (I0,53\%). De acordo com a pontuação final do AUDIT (I0,53\%) dos residentes apresentam uso de risco para o álcool. CONCLUSÃO: É fundamental que novos estudos acerca da investigação do consumo de bebidas alcoólicas sejam realizados para melhorar as políticas públicas para diminuir o uso de risco de bebidas alcoólicas.

PALAVRAS-CHAVE: Bebidas alcoólicas; Pandemia; Pessoal de saúde. 